Research Article

\title{
Field Tests' Study of Deviation Correction of Building near Excavation
}

\author{
Xi Peng $\left(\mathbb{D},{ }^{1}\right.$ Ningxin Yang $\mathbb{D}^{2},{ }^{2}$ and Mi Zhou $\mathbb{D}^{3}$ \\ ${ }^{1}$ State Key Laboratory of Subtropical Building Science, South China University of Technology, 381 Wushan Road, \\ Guangzhou 510640, China \\ ${ }^{2}$ South China University of Technology, 381 Wushan Road, Guangzhou 510640, China \\ ${ }^{3}$ State Key Laboratory of Subtropical Building Science, South China Institute of Geotechnical Engineering, \\ South China University of Technology, 381 Wushan Road, Guangzhou 510640, China
}

Correspondence should be addressed to Mi Zhou; zhoumi@scut.edu.cn

Received 5 July 2021; Revised 13 August 2021; Accepted 22 August 2021; Published 8 September 2021

Academic Editor: Chiara Bedon

Copyright $(2021$ Xi Peng et al. This is an open access article distributed under the Creative Commons Attribution License, which permits unrestricted use, distribution, and reproduction in any medium, provided the original work is properly cited.

Deviation correction of building is a big challenge for engineers. Without powerful technique for deviation, no special guidance can be followed to conduct the deviation rectification of buildings, which brings numerous failure cases. In this study, a case study was performed to provide insight into the behavior of a special technique for deviation rectification of building near excavation. The new technique was introduced firstly, and then, the field test data, in terms of lateral displacement of wall of pit, water level deviation, and soil deformation around pile of the building, were addressed to show the performance of the function of each process and the mechanism of it. The results show that this new technique for the deviation rectification of building works very well to uplift the whole building to reach the destination position (maximum uplift $=9.71 \mathrm{~cm}$ ) and meets the requirement of design demand, without negative effect on the adjacent excavation reported.

\section{Introduction}

Excavated foundation pits are often close to buildings in urban areas, which make a big challenge for engineers to make the safety of surrounding buildings. The deformation of support structure and surrounding ground subsidence is directly due to dewatering of the foundation pit and then leads to differential settlements of the surrounding buildings. Li et al. [1] found that the maximum settlement around a foundation pit can be $30 \mathrm{~mm}$ in their studies. Moreover, the effective stress in soil increases by the lowering groundwater level for well-point dewatering around foundation pit, and the new settlement of surrounding buildings is caused. Numerous cases of buildings on soft foundation with large deformation of buildings were reported. Therefore, the differential settlements of building needed to be rectified. However, the rectification of buildings is a hard task because the plastic deformation of the building foundations is very difficult to recover.
At present, the study of rectifying building deviation mainly includes field tests and numerical simulations. Grouting technique has been widely used to uplift structures, which include grouting fluids into organic grouting fluids and inorganic grouting fluids (Miao et al. [2]). Some previous works have been conducted to utilize the uplift technique through three methods, including grouting, steel pipe pile traction, and Earth hollowing, to rectify the deviation of residential buildings and ancient temple (Jia et al. [3], Zhou et al. [4], Yin et al. [5], and Yin et al. [6]), with very effective performance obtained for these three methods. Grouting uplift has been proven that it cannot only be used in building deviation rectification but also can be applied in reducing differential settlements of railway subgrades and metro tunnel and uplifting of a subway foundation findings (Bian et al. [7], Zheng et al. [8], and Zhou et al. [9]). Numerical simulations were employed to explore the soil movement mechanisms in the deviation correction process, hence access the performance of the deviation technique. 
Yin et al. [10] and Wang et al. [11] used the finite element simulation software to simulate the whole process of building deviation rectification, and they found that the FE method was effective, and the simulation results were relatively close to the measured results.

In this study, a case study of a special building deviation technique is conducted through field test monitoring, including groundwater level, horizontal displacement of adjacent soil and support structure, vertical soil displacement, and building relative tilt rate, to access the performance and mechanism of this new technique. It is found that this new technique has a significant effect on the deviation of buildings.

\section{Site Condition}

2.1. Project Profiles. This project is located in Guangzhou, south of China. The photo of this project is shown in Figure 1, which shows that the building is located in the southeast corner of the pit, at a distance of $12.9 \mathrm{~m}$ from the edge of the pit with a depth of $10.35 \mathrm{~m}$. The foundation pit design adopts the support system of rotary bored pile and reinforced concrete, with partially usage of prestressed anchor cable. The water proofing design of the foundation pit uses triaxial cement mixing piles (large diameter) to form a water stopping curtain, which need to penetrate $2 \sim 4 \mathrm{~m}$ below the bottom of the pit. The layout of the excavation and building is shown in Figure 2. The process of the foundation pit construction contain five steps, including Step 1: locate the position of the foundation pit and mark it on-site; Step 2: construct the main structure piles, triaxial cement mixing piles, supporting piles, columns, and rotary spray piles; Step 3: construct the top beam of the foundation pit supporting piles and reinforced concrete internal support (partial anchor cable); Step 4: excavate the Earth to the bottom of the foundation pit and hang the net between the piles spray concrete protection; Step 5: construction of basement structure and replacement of bracing backfill. The building is a five-storey frame structure residential building, and its foundation is independent foundation, with its foundation size being $1.5 \mathrm{~m} \times 2 \mathrm{~m}$ square individual foundation. The design requirement of the foundation bearing capacity is $150 \mathrm{kPa}$, and the building foundation buried depth is $1.5 \mathrm{~m}$.

Concrete strength grade was tested by drilling cores and four sets of samples were taken, with the axial compressive strength of the concrete ranging from $14.5 \mathrm{MPa}$ to $18.6 \mathrm{MPa}$. The axial compressive strength of the structural columns was tested by the rebound method, with the axial compressive strength ranging from 16.4 MPa to 20.2 MPa. The aggregate of concrete obtained from the core drilling was well distributed and densely cemented, but the steel reinforcement was corroded by slight rusting.

During the excavation of the foundation pit, the relative tilt rate of the building has been increased to beyond the requirement of the design code, with the relative tilt rate measured at the point $s_{f 4}$ in the northeast direction rapidly increasing to $2.296 \%$ and the settlement ranging from 58 to $81.3 \mathrm{~mm}$. These large settlements were induced by the water level decrease that was induced by the pumping water during the construction. Therefore, the large differential settlement of building makes it tilted, and deviation correction is needed.

The sectional drawing of the building is shown in Figure 3. The soil parameters of the soil samples and the parameters of the pit support structure are shown in Table 1. Soil profile around the tower base is divided into five layers according to the drilling depth (see Figure 3). The main bearing layer of the building foundation is soft-plastic silty clay and flow-plastic silt.

2.2. Instrumentation. In this project, the relative tilt rate of the building, the settlement of four corners of the building and the surface of adjacent soil, the deformation of the support structure of the foundation pit, and the horizontal displacement of adjacent soil were measured. Figure 4 shows the planar layout of the measuring points and lists the monitoring items and the corresponding instrumentation, where the triangle symbol denotes placement of the prism of total station, WT denotes the groundwater level measuring point, and LD denotes the embedding point of the inclinometer tube.

2.3. Rectification Process. Rectification involves drill recharge wells, drill slanting steel pipe, and grout mixture of cement slurry and water glass solution, add steel pipe piles, add raft, and carry out the construction of vertical steel pipe piles and grouting at the reserved orifice and the core of the steel pipe piles. Simply following previous results measured for this 5-storey reinforced concrete structure, such as the concrete strength grade and the bearing capacity of the main layer of foundation soil, the rectifying procedure should include six phases, as shown in Figure 5.

The first phase is to drill recharge wells on the ground between the building and the foundation pit. The wells should be filled with almost 200-300 cubic meter of water a day to allow the originally falling water table to rise back up and reduce the settlement of the building foundations. The second phase is to drill slant grouting steel pipes on the ground between the building and the foundation pit, as shown in Figure 3. Mixture of cement slurry and water glass solution should be grouted through the pipes into the foundation soil from the core of the steel pipe pile. Cement slurry water-cement ratio 0.4 to 0.5 , water glass diluted at 1 : 2, grouting pressure more than 0.5 to $1.2 \mathrm{MPa}$, double slurry ratio about $1: 1$ to $1: 0.8$, solidification time control not more than $30 \mathrm{~s}$, and single grouting volume (cement slurry) not the slurry is injected at intervals of 3 to 4 hours, depending on the deformation of the building, intermittently to reinforce the base subsoil. At the same time, in the vicinity of the large settlement, 4 deep grouting holes are designed in the steel pipe piles, and the soil is lifted by grouting the pile bottom with mixture of cement slurry and water glass solution, in order to realize the zonal lifting of the foundation. The third phase is to add vertical steel pipe piles to the foundation of the building to stand part of the vertical load. Mixture of cement slurry and water glass solution should be grouted at the bottom of the steel pipe piles to locally lift the 


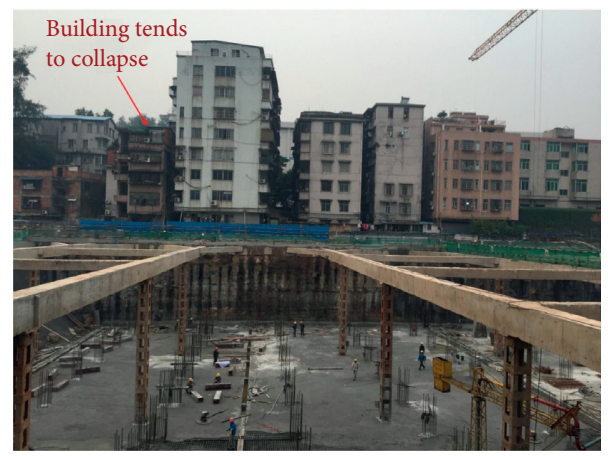

Figure 1: Project site photo.

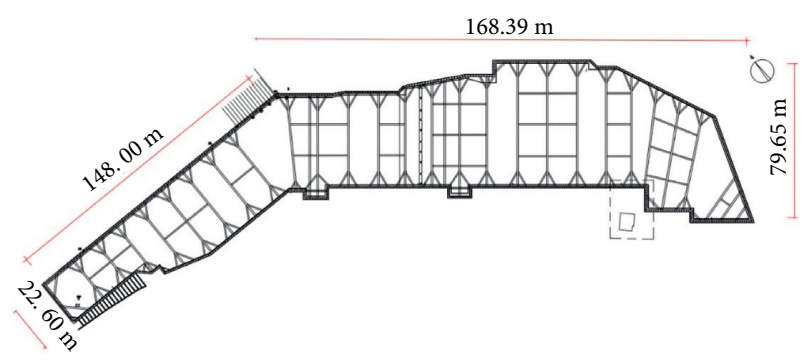

(a)

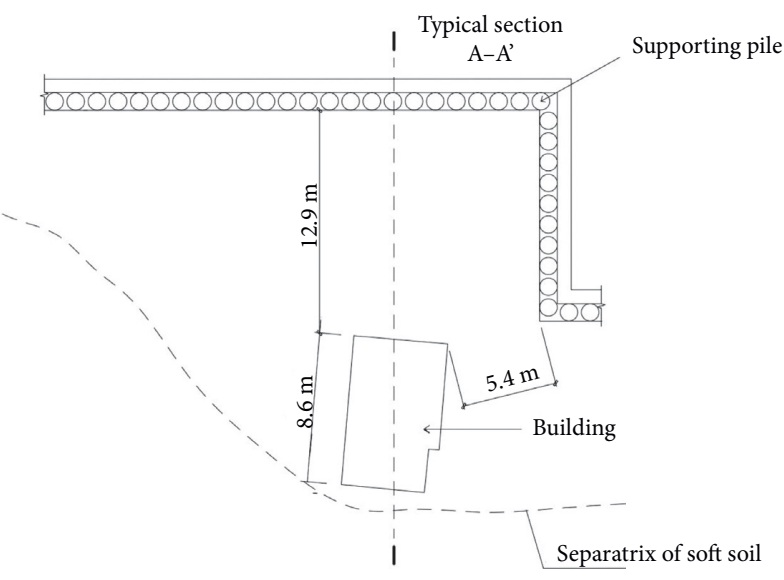

(b)

Figure 2: (a) Layout of the foundation pit. (b) Layout of the building.

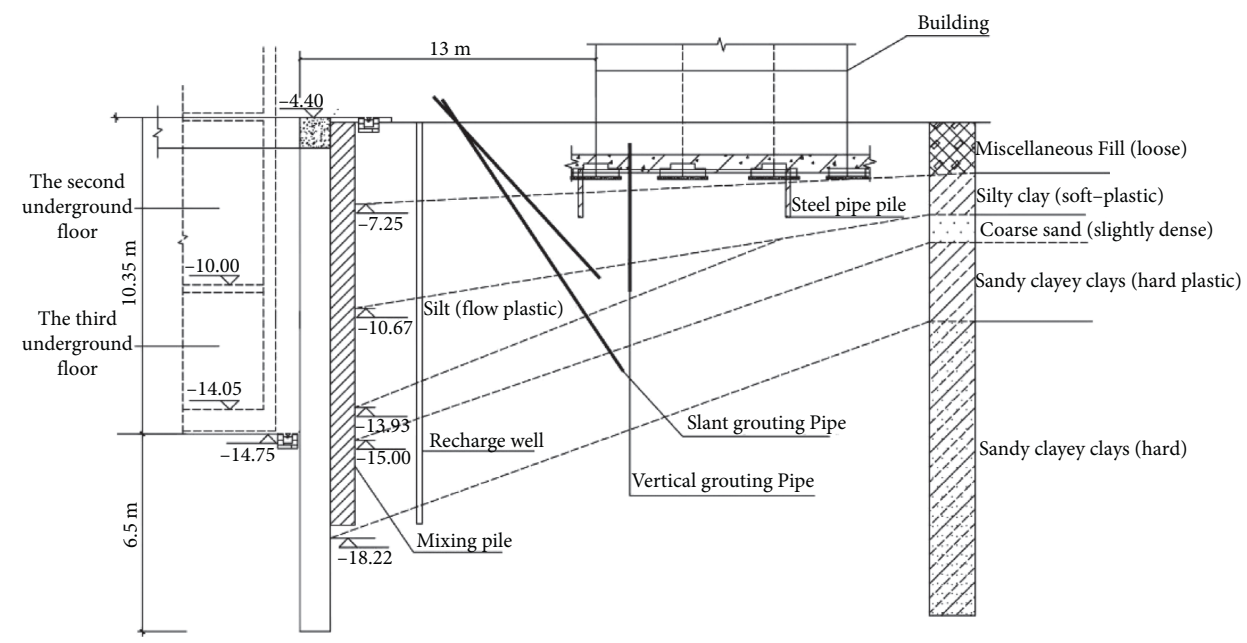

FIgURE 3: Typical section (A-A') drawing.

soil and prevent the collapse of the house. The fourth phase is to strengthen the building's foundation by using $600 \mathrm{~mm}$ raft slabs. In this phase, the individual foundations of the building are connected as a whole to furtherly increase the foundation stiffness and preventing the building from keeping settling during the correction process. The fifth phase is the construction of vertical steel pipe piles with their design capacity being 150 (200) $\mathrm{kN}$ and their thickness being of $6(8) \mathrm{mm}$. In this phase, piles are formed by means of static anchor pressure. The purpose of this step is to reduce the load on the foundation soil to further reduce the building settlement. The sixth phase is to gradually lift the foundation 
TABLE 1: Soil properties and parameters.

\begin{tabular}{|c|c|c|c|c|c|c|c|c|c|c|c|c|c|}
\hline Name & $E(\mathrm{MPa})$ & $\gamma\left(\mathrm{kN} / \mathrm{m}^{3}\right)$ & $v$ & $c(\mathrm{kPa})$ & $\varphi\left({ }^{\circ}\right)$ & $\omega(\%)$ & $\omega_{L}(\%)$ & $\omega_{p}(\%)$ & $N$ & Thickness $m$ & $e$ & $\begin{array}{c}a_{1-2} \\
\left(\mathrm{MPa}^{-1}\right)\end{array}$ & $E_{\mathrm{s}}(\mathrm{MPa})$ \\
\hline Miscellaneous fill & 6 & 19.5 & 0.35 & 8 & 14 & 31.4 & 37.5 & 26.2 & 4.7 & $1.30 \sim 1.80$ & 0.876 & 0.48 & 4.68 \\
\hline Silty clay & 12 & 19.8 & 0.32 & 12 & 8 & 39.2 & 43.2 & 27.0 & 3.6 & $1.20 \sim 3.40$ & 1.088 & 0.49 & 4.57 \\
\hline Silt & 2 & 19.9 & 0.40 & 8 & 6 & 58.8 & 56.0 & 37.8 & 1.2 & $0.50 \sim 4.30$ & 1.657 & 1.08 & 2.76 \\
\hline Coarse sand & 25 & 20.1 & 0.28 & 0 & 30 & 8.1 & - & - & 7.5 & $0.50 \sim 2.40$ & 0.867 & 0.12 & 11.42 \\
\hline Sandy clay ${ }^{(1)}$ & 150 & 20.5 & 0.25 & 40 & 33 & 29.7 & 37.2 & 25.3 & 16.4 & $1.20 \sim 10.00$ & 0.892 & 0.46 & 4.26 \\
\hline Sandy clay ${ }^{2}$ & 180 & 20.9 & 0.23 & 60 & 35 & 25.0 & 34.4 & 22.0 & 25.9 & $0.90 \sim 7.90$ & 0.778 & 0.36 & 5.10 \\
\hline Granite & 300 & 22.5 & 0.22 & 100 & 38 & - & - & - & - & - & - & - & - \\
\hline Grouting area & 50 & 19.9 & 0.32 & 30 & 28 & - & - & - & - & - & - & - & - \\
\hline Supporting pile & $3.0 \times 10^{4}$ & 24 & 0.22 & - & - & - & - & - & - & - & - & - & - \\
\hline $\begin{array}{l}\text { Horizontal } \\
\text { support }\end{array}$ & $3.0 \times 10^{4}$ & 24 & 0.22 & - & - & - & - & - & - & - & - & - & - \\
\hline
\end{tabular}

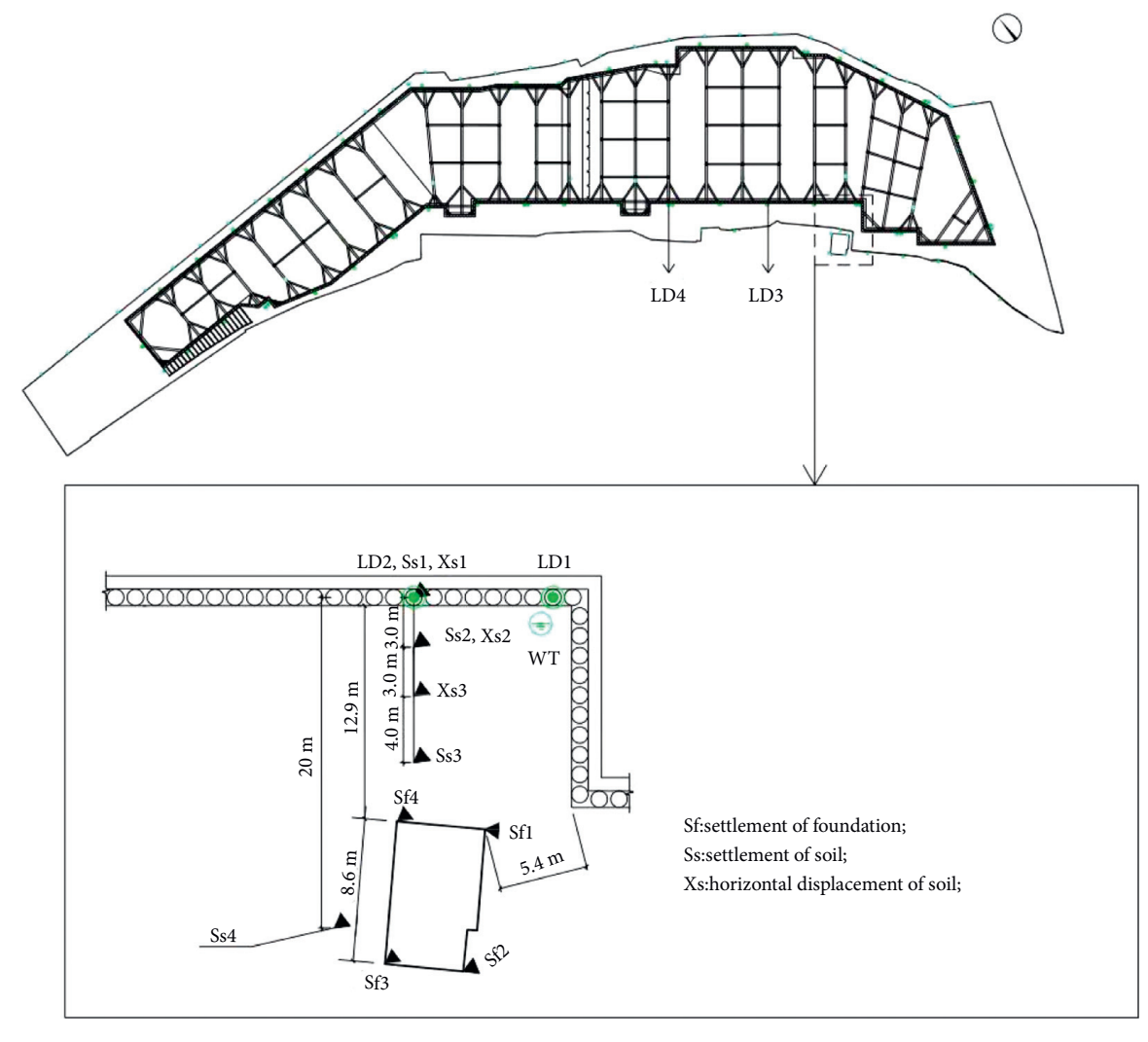

- LD (Lateral Displacement) :Embedding point of inclinometer tube;

$=$ WT (Water table) :Groundwater table measuring point;

- Placement point of total station prism;

FIGURE 4: Site monitoring layout for rectification works.

soil. In this phase, the mixture of cement slurry and water glass solution should be grouted in small quantities and in sections at the reserved grouting apertures and the base of vertical steel pipe piles. Grouting can only be stopped when the building relative tilt rate is less than $0.8 \%$.

\section{Results and Discussion}

3.1. The Relative Tilt Rate of the Building. The relative tilt rates of the building at the north-east and north-west were measured by total station at $s_{\mathrm{f} 1}$ point and $s_{\mathrm{f} 4}$ are shown in Figure 6, from which it can be seen that the building was leaning before the pit was constructed. According to the statistic of two monitoring points, the relative tilt rates of the building before the first stage of building deviation rectification are $1.923 \%$ and $0.572 \%$, respectively, at the point of $s_{f 4}$ in the northeast and northwest directions and $0.59 \%$ and $0.762 \%$, respectively, at the point of $s_{f 4}$ in the northeast and northwest directions. It also shows that the relative tilt rates increase slowly before reaching the maximum settlement, 


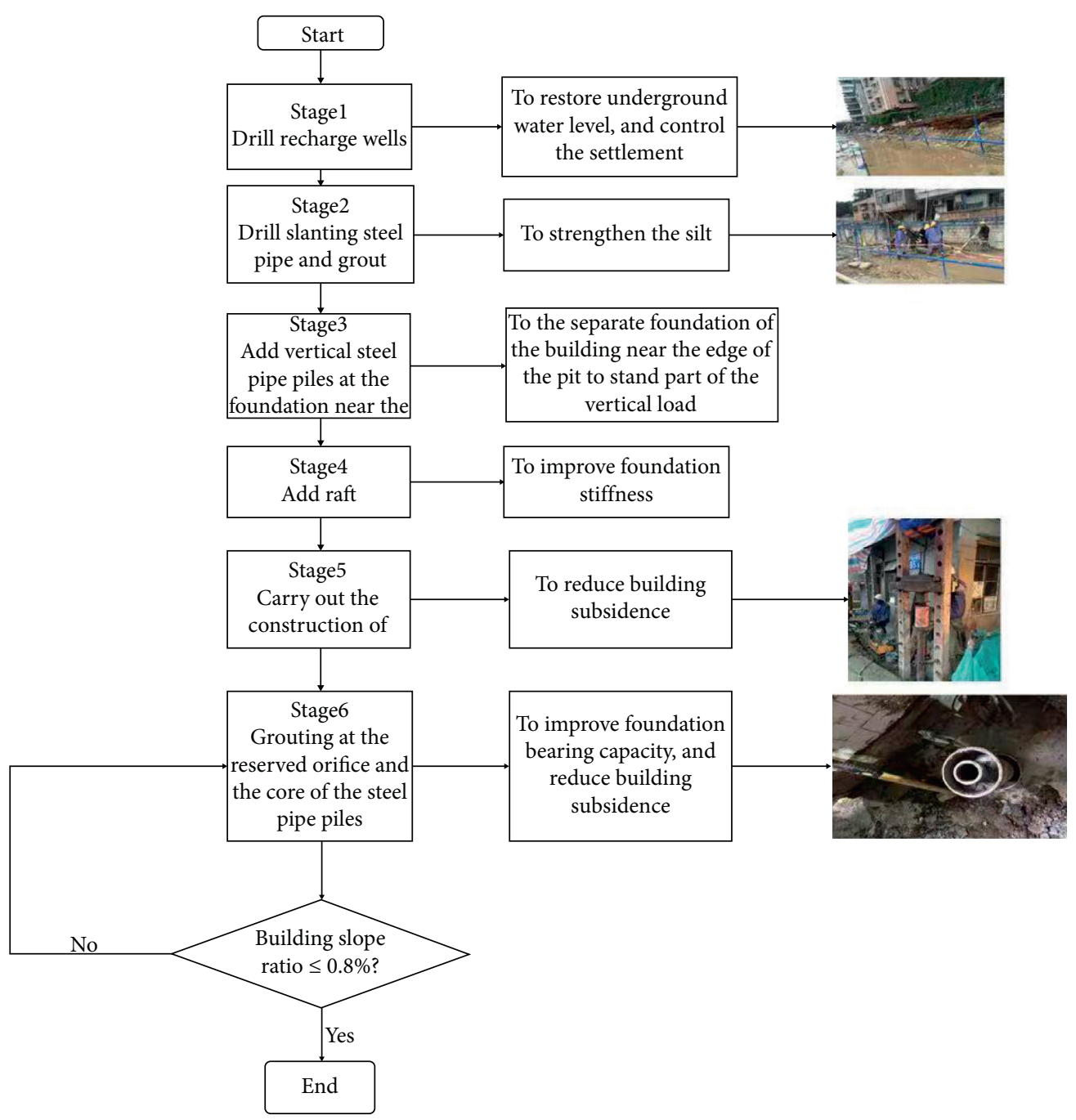

FIGURE 5: Working principal diagram of rectifying engineering.

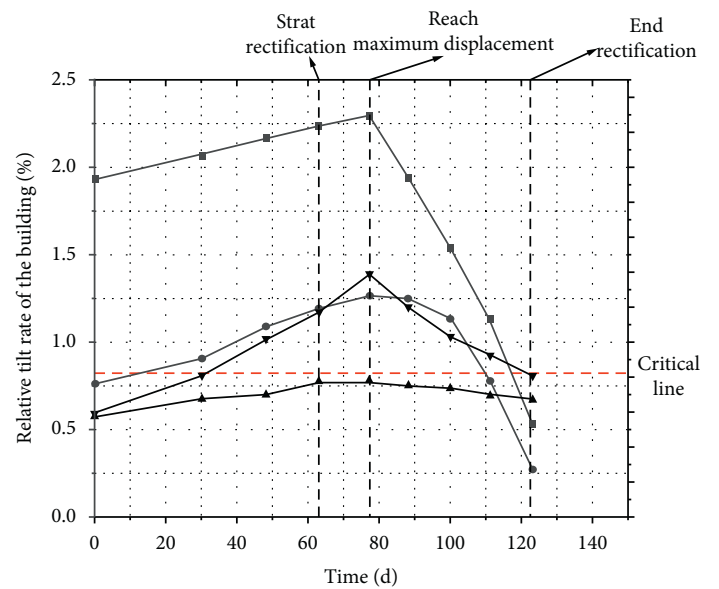

- Observed at Sf4 in northeast direction

- Observed at Sf1 in northeast direction

- Observed at Sf4 in northwest direction

- Observed at Sfl in northwest direction

Figure 6: The tilt angle of the building in the whole process. and after reaching the maximum settlement, the relative tilt rates decrease significantly due to the rise of the groundwater level, the support of the steel pipe piles, and the effect of grouting uplifts. After the building deviation rectification, the relative tilt rates at points of $s_{\mathrm{f} 1}$ and $s_{\mathrm{f} 4}$ in the NE and NW directions measured at the two points decreased to $0.27 \%$, $0.81 \%, 0.53 \%$, and $0.67 \%$, respectively, both of which were less than the $\sim 0.8 \%$ specified in the standard [12]. Zhou et al. [4] found, for a case on the grout lifting of the leaning pagoda of Dinglin Temple, that the leaning pagoda of Dinglin Temple was rectified, and its tilt angle was reduced from $7^{\circ} 59^{\prime}$ to $5^{\circ} 36^{\prime}$.

3.2. Variation of Water Level of Typical Water Level Holes. The groundwater level in observation well decreases during the construction of the foundation pit. Figure 7 shows that the settlement of the pile head induced by the water level variation, which is decreased close to $10 \mathrm{~m}$. Due to the sandy clay is under the support layer of the building, the 


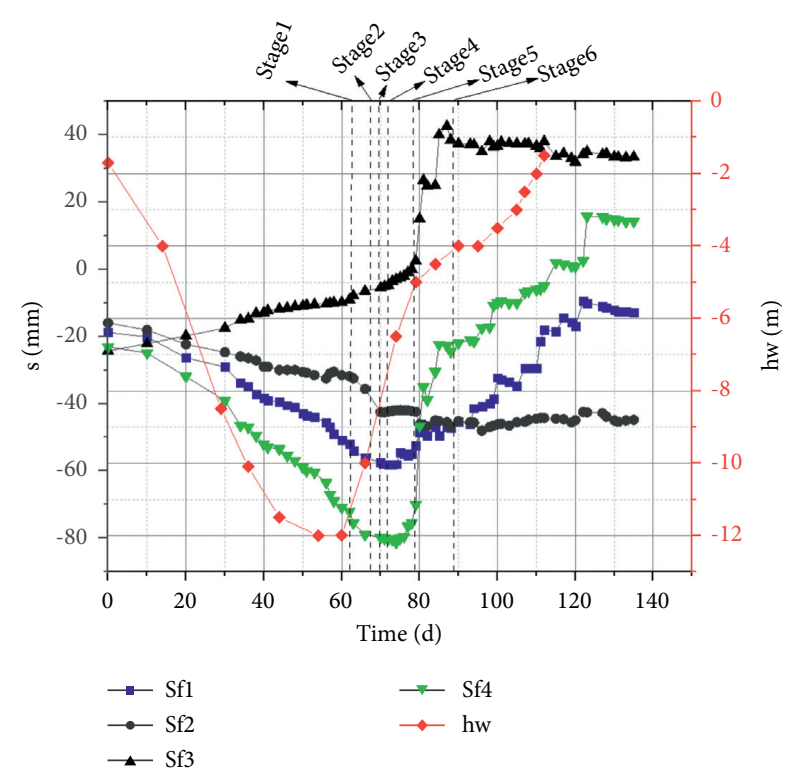

FIgURE 7: Surface settlement of four corners of the building.

permeability coefficient of the sandy clay is greater than that of the supporting layer. Because the water stop curtain only enters $3 \mathrm{~m}$ below the bottom of the pit, the groundwater has been bypassing the bottom of the water stop curtain to the foundation pit since the excavation of the foundation pit. Also, nearby residents have drilled and set up a water extraction well of about $40 \mathrm{~m}$ to continuously pump out groundwater, which has aggravated the fall of the groundwater level. Eventually, the groundwater level has fallen to a position close to the bottom of the pit.

After the rectification of the building began, the groundwater level began to rise gradually because $200-300 \mathrm{~m}^{3}$ of water was recharged into the recharge well daily, eventually returning to the position before the foundation pit was excavated. Li and Zheng [13] also found that the groundwater leakage occurred during the excavation of the pit due to problems with the water stop structure, but the water level drop was small, with only $3 \mathrm{~m}$ in their study of a foundation pit project.

3.3. Settlement of Four Corners of the Building. The settlement development of four corners of the building is shown in Figure 7. Before the construction of building deviation rectification, the monitored settlement curves can be divided into two types:

(1) At points $s_{\mathrm{f} 1}, s_{\mathrm{f} 3}$, and $s_{\mathrm{f} 4}$, the settlement occurs. When the excavation is started, the settlement begins to develop at the monitoring points. The settlement velocity at the point $s_{\mathrm{f} 4}$ is rapid, and the maximum settlement reaches $58.2 \mathrm{~mm}$. The settlement velocity at the point $s_{\mathrm{f} 2}$ is relatively slow, and the total settlement is only $10 \mathrm{~mm}$.

(2) The uplift occurs at point $s_{\mathrm{f} 2}$. When the excavation is started, the uplift begins to develop at the monitoring points. The maximum uplift value at point $s_{\mathrm{f} 2}$ is $14.5 \mathrm{~mm}$.
After the building deviation rectification was carried out, the curves at points $s_{\mathrm{f} 1}, s_{\mathrm{f} 3}$, and $s_{\mathrm{f} 4}$ indicate that the uplift value of each monitoring point is proportional to time with the progress of the grouting process. The maximum uplift value at points $s_{\mathrm{f} 1}, s_{\mathrm{f} 3}$, and $s_{\mathrm{f} 4}$ are $56.4 \mathrm{~mm}, 43.2 \mathrm{~mm}$, and $97.1 \mathrm{~mm}$, respectively. However, settlement still occurs at the point of $s_{\mathrm{f} 2}$ in order to maintain the level of the whole building floor after the correction. Schweiger et al. [14] also used the grout lifting method when studying the correction of a steel oil tank that had undergone differential settlement, and the grouting points were arranged symmetrically with the center of the steel tank as the axis of symmetry. The measurement results of the field tests showed that the maximum lifting volume was nearly $170 \mathrm{~mm}$ (the total grouting volume was about $10,200 \mathrm{~m}^{3}$ ), so there is a clear difference in the grouting volume between this. Therefore, the maximum lifting volume of the two cases is different.

3.4. Settlement of Surrounding Soil. The settlement of the soil around foundation is shown in Figure 8. Before the construction of building deviation rectification, the monitored settlement curves are founded that the settlement occurs, and the settlements depend on the distance the points to the foundation pit. However, the reason of subsidence of these four points is different. The settlement of the top of the foundation support pile $\left(s_{\mathrm{s} 1}\right)$ increased slowly because the Earth pressure acting on the support pile is increasing slowly as the excavation becomes deeper and deeper. The settlement at $s_{\mathrm{s} 2}$ point kept increasing after the excavation of the pit because this point was for vehicles passing by and stacking next to the foundation pit. As for the points $s_{\mathrm{s} 3}$ and $s_{\mathrm{s} 4}$, the settlement at $s_{\mathrm{s} 3}$ and $s_{\mathrm{s} 4} \mathrm{kept}$ increasing because of the influence of the building subsidence.

After building deviation rectification was carried out, the curves at $s_{\mathrm{s} 3}$ and $s_{\mathrm{s} 4}$ indicate that the uplift value of each monitoring point is proportional to the time with the progress of the grouting process. However, the curves at $s_{\mathrm{s} 1}$ and $s_{\mathrm{s} 2}$ only stay stable because the distance between two points and grouting points is larger than $9 \mathrm{~m}$. When the grouting is stopped, the surface uplift value will stabilize. The point $s_{\mathrm{s} 3}$ was lifted by $75.3 \mathrm{~mm}$, and the point $s_{\mathrm{s} 4}$ was lifted by $14.6 \mathrm{~mm}$. Ong et al. [15] found a similar phenomenon when observing soil movement induced by excavation in clay by the centrifuge model test. They found that, after completion of excavation, the soil continues to settle with time while the rate of increase in settlement decreases with time. Yang et al. [16] found that the settlement of the top of the supporting pile could reach a maximum of $6 \mathrm{~mm}$ when they studied the displacement of the supporting structure of a deep foundation pit using a pile anchor support structure. Guo et al. [17] summarized a formula for predicting the lift of the soil surface during slurry injection based on previous research and did field tests to compare the predicted and measured values. They found that the surface uplift at a location around $3 \mathrm{~m}$ from the grout center point was around $4 \mathrm{~mm}$ when the grouting depth was $8 \mathrm{~m}$.

3.5. Horizontal Displacement of Surrounding Foundation Soil. The horizontal displacements of the soil around foundation are shown in Figure 9. It can be seen from Figure 9 that 


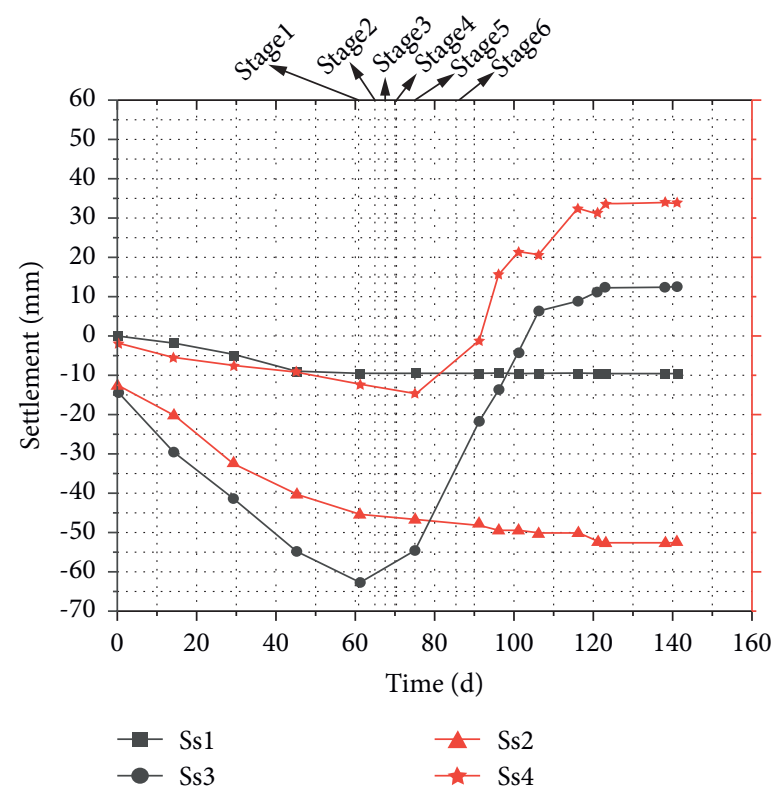

FIGURE 8: Settlement of the soil around foundation.

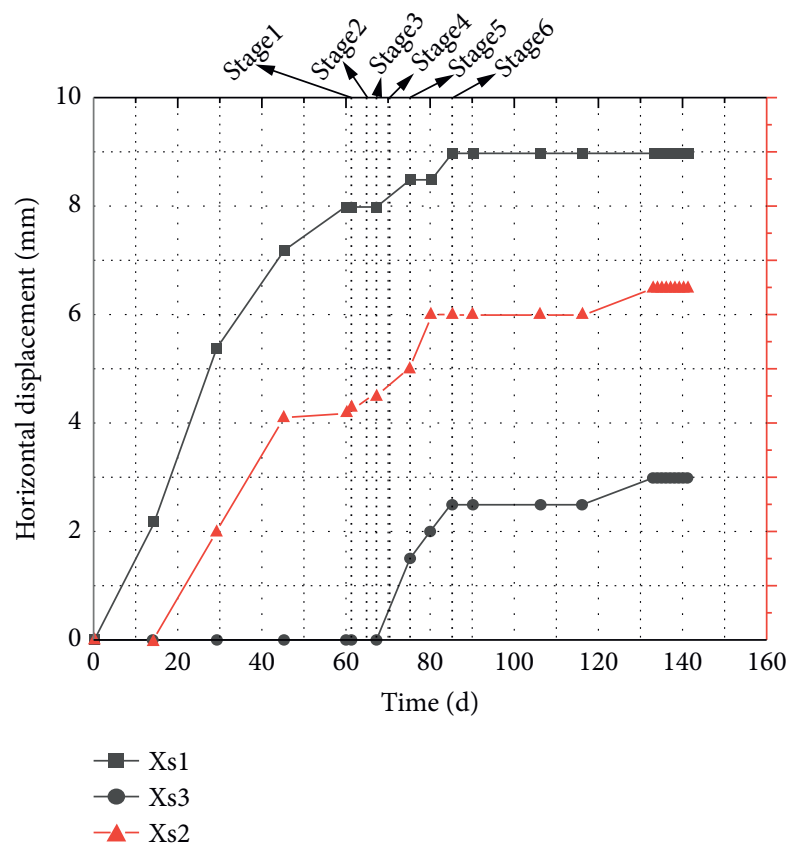

Figure 9: Horizontal displacements the soil around foundation.

horizontal displacements with construction are presented as a step-by-step process which are increased at first and then tended to stable. Horizontal displacements tend to increase with excavation, and the growth became slow after building deviation rectification was carried out and then finally tended to stable. The reasons for this phenomenon can be attributed to the increase in Earth pressure acting on the supporting pile and the pressure of trucks and stacks. The maximum horizontal displacement at the top of the supporting pile is $9.5 \mathrm{~mm}$. The maximum horizontal displacements in the two points of $x_{\mathrm{s} 2}$ and $x_{\mathrm{s} 3}$ were $6.5 \mathrm{~mm}$ and
$3 \mathrm{~mm}$, respectively. Yang et al. [16] conducted tests to monitor the data of a foundation pit supported by a pileanchor structure and excavated to a depth of 8-13 $\mathrm{m}$ in their study. It was found that the maximum horizontal displacement of the top of the supporting pile reached $16 \mathrm{~mm}$. Zheng et al. [18] found that the radial stress decreases to $0 \mathrm{~mm}$ at distances greater than $1 \mathrm{~m}$ from the grouting point in their study on numerical modeling and verification of grouting with mold bag treatment on seepage failure in foundation excavation. From this finding, it can be concluded that the horizontal displacements at the two points 


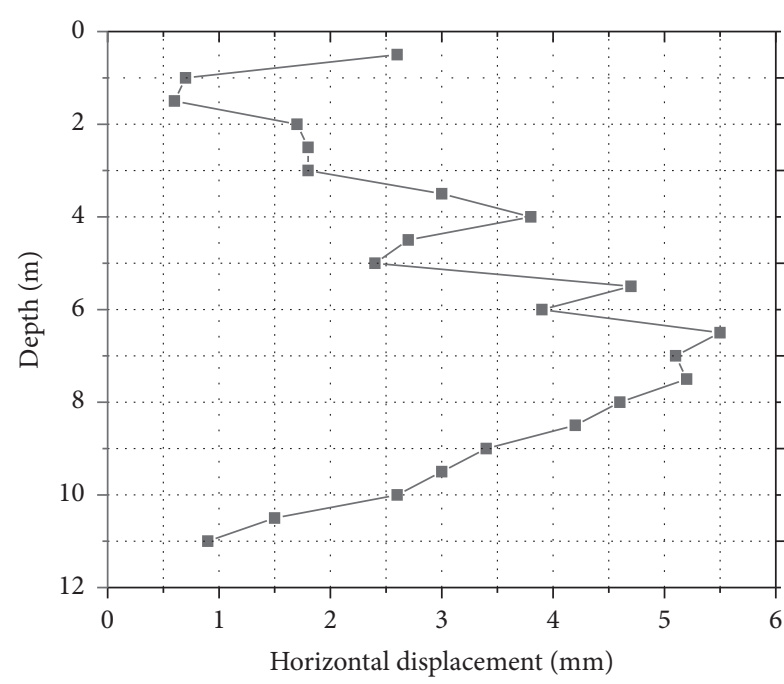

(a)

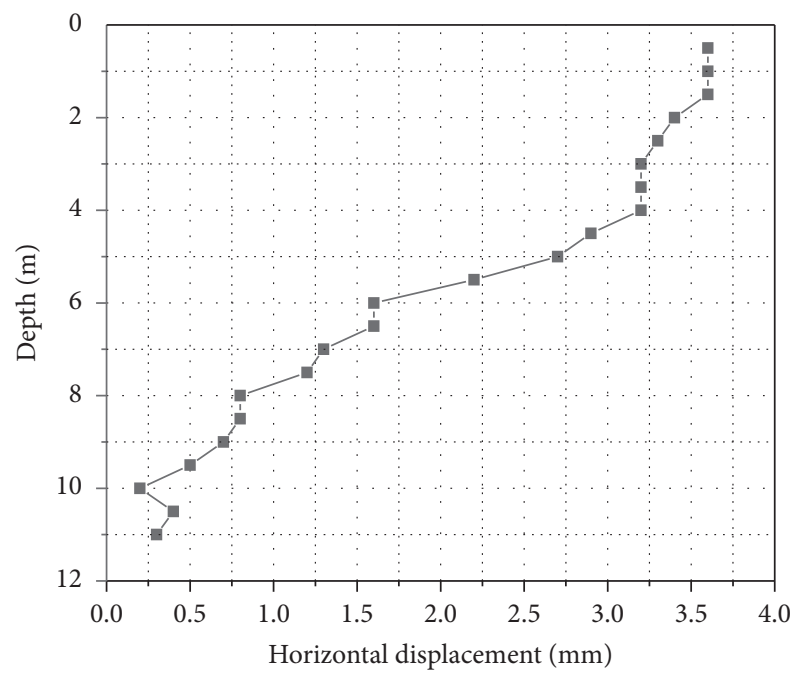

(c)

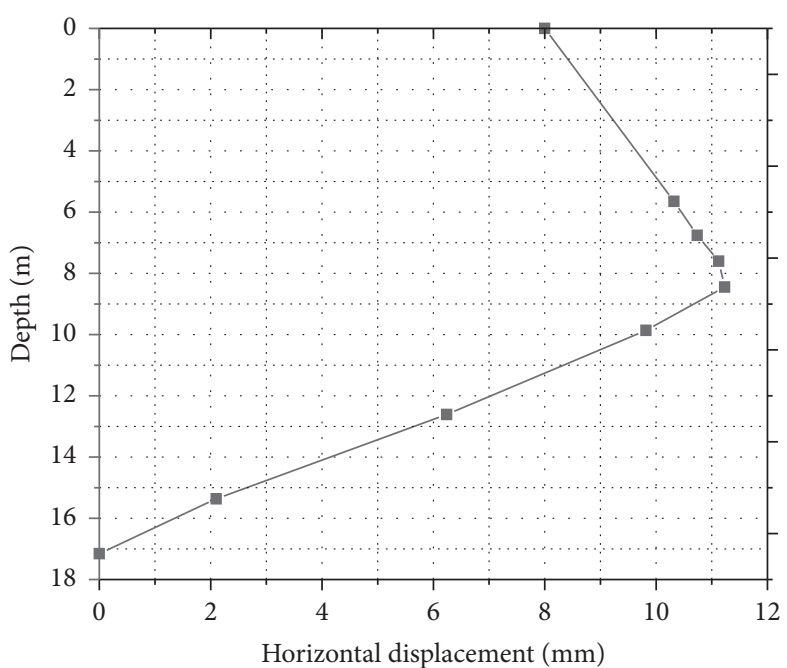

(b)

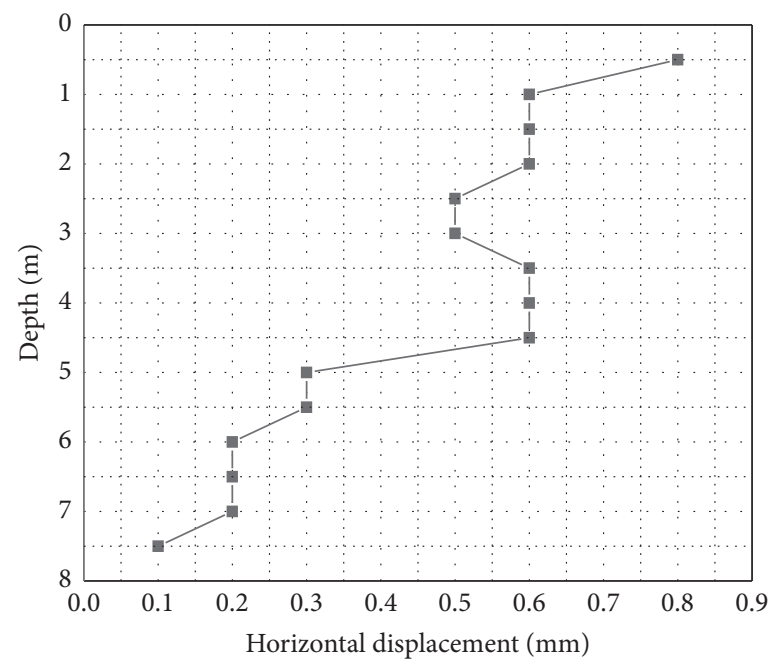

(d)

FIGURE 10: Horizontal displacements of wall of the excavation. (a) LD1. (b) LD2. (c) LD3. (d) LD4.

$3 \mathrm{~m}$ and $6 \mathrm{~m}$ from the edge of the foundation excavation are not caused by grouting because their distance to the grouting point is much greater than $1 \mathrm{~m}$.

3.6. Lateral Slope of Supporting Pile. The measured value of lateral slope of supporting pile at points LD1-4 is shown in Figure 10. The horizontal displacement of the supporting pile body has remained unchanged after the excavation of the foundation pit was completed because the Earth pressure acting on the supporting pile body has remained unchanged after the excavation of the foundation pit is completed. Also, the maximum deflection of the supporting pile was $12 \mathrm{~mm}$, which was less than design requirement of $30 \mathrm{~mm}$ [19]. Tang et al. [20], Wang et al. [21], and Zhang [22] all measured the variation of the horizontal displacement of the supporting structure of foundation pit with depth due to the effect of Earth pressure in their own field tests or numerical simulations. The horizontal displacement at the midpoint of the long side of the support structure from the excavation completion of the first layer to the completion of major structure has been increasing, but the curves of the horizontal displacement at the midpoint of the long side of the support structure were measured at each time point. Chong and Ong [23] also studied the deflection of contiguous bored pile wall affected by accidental groundwater drawdown. The largest horizontal wall deflection was $14.3 \mathrm{~mm}$ in the final stage of construction, which was similar to the data in this project.

\section{Conclusions}

Field tests were conducted to study the behavior of a special technique of deviation correction of building. Based on the tests data, some findings can be drawn as follows:

(1) A new technique for the deviation rectification of building has been described in detail, and it works 
very well to uplift the whole building to reach the destination position, which can meet the requirement of design demand.

(2) The new technique can provide uplift step by step with the reinforcement of ground and can reach $9.71 \mathrm{~cm}$ displacement.

(3) The new technique does not exaggerate deflection of the retaining structure of adjacent excavation, and the deflection of the retaining structure of adjacent excavation can meet the design requirement (maximum deflection $=14.3 \mathrm{~mm}<30 \mathrm{~mm}$ ).

\section{Notations}

$\begin{array}{ll}E: & \text { Elastic modulus } \\ \gamma: & \text { Weight density } \\ \nu: & \text { Poisson ratio } \\ c: & \text { Cohesion force } \\ \varphi: & \text { Internal friction angle } \\ \omega: & \text { Water content } \\ \omega_{L}: & \text { Liquid limit } \\ \omega_{p}: & \text { Plastic limit } \\ N: & \text { Standard penetration number } \\ e: & \text { Void ratio } \\ a_{1-2}: & \text { Compression coefficient } \\ E_{\mathrm{s}}: & \text { Compressive modulus. }\end{array}$

\section{Data Availability}

All data of the field tests in this study are available from the corresponding author upon request.

\section{Conflicts of Interest}

The authors declare that they have no conflicts of interest.

\section{Acknowledgments}

This research was supported by the Guangdong Basic and Applied Basic Research Foundation (2021A1515010828 and 2020A1515410001), State Key Laboratory of Hydraulic Engineering Simulation and Safety, and Tianjin University. These supports are appreciated.

\section{References}

[1] Y. Li, Z. Z. He, G. H. Yan, and F. Y. Han, "Foundation pit dewatering and ground subsidence in binary structural stratum of Wuhan," Advanced Materials Research, vol. 639640, pp. 694-699, 2013.

[2] Q. Q. Miao, Q. Q. Zhu, and S. P. Jiang, "Application of grouting technology in the geotechnical engineering," Applied Mechanics and Materials, vol. 744-746, pp. 442-446, 2015.

[3] G. Jia, "Research on the application of deviation correction technology in building reinforcement," in Proceedings of the 3rd International Conference on Advances in Materials, Machinery, Electronics (AMME 2019), Wuhan, China, January 2019.

[4] M. Zhou, X. Su, J. Lei, and S. Fang, "Foundation reinforcement and deviation rectification of the leaning pagoda of Dinglin Temple, China," Proceedings of the Institution of Civil
Engineers-Geotechnical Engineering, vol. 173, no. 6, pp. 473484, 2020.

[5] H. P. Yin, C. L. Li, and Z. Y. Xie, "Analysis on deviation rectification and reinforcement of buildings," Advanced Materials Research, vol. 255-260, pp. 59-64, 2011.

[6] H. Yin, H. S. Qiu, and X. Q. Zhang, "Study and application of settlement resistance and correction method of a residential building," Applied Mechanics and Materials, vol. 621, pp. 89-94, 2014.

[7] X. Bian, X. Duan, W. Li, and J. Jiang, "Track settlement restoration of ballastless high-speed railway using polyurethane grouting: full-scale model testing," Transportation Geotechnics, vol. 26, Article ID 100381, 2021.

[8] Z. Zheng, R. Liu, S. Li, and H. Yang, "Control of ground uplift based on flow-field regularity during grouting in fracture with flowing groundwater," International Journal of Geomechanics, vol. 20, no. 3, Article ID 04020014, 2020.

[9] S. Zhou, J. Xiao, H. Di, and Y. Zhu, "Differential settlement remediation for new shield metro tunnel in soft soils using corrective grouting method: case study," Canadian Geotechnical Journal, vol. 55, no. 12, pp. 1877-1887, 2018.

[10] H. Yin, L. Chunlin, and X. Zhongyou, "Finite element simulation of building deviation rectification through excavation," in Proceedings of the 2011 International Conference on Electric Information and Control Engineering, pp. 5043-5046, Wuhan, China, April 2011.

[11] Y. Wang, X. H. Wang, and M. Zhang, "Research on mechanisms and ground uplifting effects by grouting taken the grouting-soil-building interaction into account," Trans Tech Publications, vol. 163, pp. 3488-3498, 2011.

[12] China Architecture \& Building Press, GB 50007-2011, Code for Design of Building Foundation, China Architecture \& Building Press, Beijing, China, 2015, https://www.chinesestandard.net/.

[13] X. Li and Y. Zheng, "Monitoring and analysis of soft foundation pit with braced structure of bored cast-in-place pile," in Proceedings of the 2011 International Conference on Electrical and Control Engineering, pp. 5342-5345, Yichang, China, September 2011.

[14] H. F. Schweiger, C. Kummerer, R. Otterbein, and E. Falk, "Numerical modelling of settlement compensation by means of fracture grouting," Soils and Foundations, vol. 44, no. 1, pp. 71-86, 2004.

[15] D. E. Ong, C. E. Leung, and Y. K. Chow, "Pile behavior due to excavation-induced soil movement in clay. i: stable wall," Journal of Geotechnical and Geoenvironmental Engineering, vol. 132, no. 1, pp. 36-44, 2006.

[16] X. H. Yang, F. W. Wu, T. Chen, and X. Liu, "Analysis of monitoring results of a deep foundation pit with pile-anchor retaining structure," Applied Mechanics and Materials, vol. 580-583, pp. 28-33, 2014.

[17] F.-Q. Guo, X.-T. Liu, W.-Q. Tong, and Z. Shan, "Prediction of ground surface displacement caused by grouting," Journal of Central South University, vol. 22, no. 9, pp. 3564-3570, 2015.

[18] Z. Zheng, R. Liu, S. Li, and Q. Zhang, "Numerical modeling and verification of grouting with mold bag treatment on seepage failure in foundation excavation," Geomatics, Natural Hazards and Risk, vol. 9, no. 1, pp. 1172-1185, 2018.

[19] China Architecture \& Building Press, JGJ 120-2012, “Technical Specification for Retaining and Protection of Building Foundation Excavations," China Architecture \& Building Press, Beijing, China, 2012, https://www.chinesestandard.net/.

[20] Y.-Q. Tang, J.-J. Yan, Z.-J. Sun, and J. Zhou, "Measurement analysis of bohai bank deep foundation pit project in tianjin 
soft soil area," Engineering Geology for Society and Territory-Volume 4, Springer, Berlin, Germany, pp. 17-24, 2014.

[21] G. X. Wang, X. L. Sun, and W. P. Zhao, "Influence of excavation of complex foundation pit on surrounding environment," IOP Conference Series: Materials Science and Engineering, IOP Publishing, vol. 423, Article ID 012022, 2018.

[22] Q. Zhang, "Deformation analysis of deep foundation pit excavation in China under time-space effect," Geotechnical Research, vol. 7, no. 3, pp. 146-152, 2020.

[23] E. E.-M. Chong and D. E.-L. Ong, "Data-driven field observational method of a contiguous bored pile wall system affected by accidental groundwater drawdown," Geosciences, vol. 10 , no. 7 , p. 268,2020 